\title{
Educação Profissional e Tecnológica: análises e perspectivas da LDB/1996 à CONAE 2014
}

\author{
Anthone Mateus Magalhães Afonso a \\ Wania Regina Coutinho Gonzalez ${ }^{b}$
}

\section{Resumo}

Esse artigo tem como objetivo analisar a concepção de Educação Profissional e Tecnológica no Brasil em documentos recentes de grande importância nas definições das políticas públicas de ensino. É realizada uma análise documental compreendendo a Lei de Diretrizes e Bases da Educação - Lei no 9.394/1996, os decretos no 2.208/1997 e n ${ }^{\circ} 5.154 / 2004$, a Lei n ${ }^{\circ} 13.005 / 2014$, que trata do Plano Nacional de Educação no decênio 2014-2024, e os documentos final e referência das Conferências Nacionais de Educação de 2010 e 2014. Nesses documentos, foram encontrados e destacados alguns indícios de defesa de diferentes concepções de Educação Profissional e Tecnológica, e identificada uma grande importância conferida às Conferências Nacionais de Educação na articulação e construção das políticas educacionais e do Plano Nacional de Educação vigente.

Palavras-chave: Educação Profissional e Tecnológica. PNE. CONAE. Trabalho e educação.

\section{Introdução}

A Educação Profissional e Tecnológica (EPT) é historicamente influenciada por diferentes concepções de formação, dentre elas a que defende uma formação voltada para atender aos anseios dos arranjos produtivos, ao modelo de desenvolvimento econômico, implicando em uma formação tecnicista com foco no mercado de trabalho; ou a que almeja uma formação profissional humanista, unitária ou na perspectiva da politecnia, com foco na formação integral do trabalhador. Essas

\footnotetext{
a Instituto Federal de Educação, Ciência e Tecnologia Fluminense - IF Fluminense. Campos dos Goytacazes, Rio de Janeiro, Brasil.

b Universidade Estácio de Sá - UNESA, Programa de Pós-graduação em Educação e Cultura Contemporânea. Universidade do Estado do Rio de Janeiro - UERJ, Faculdade de Educação da Baixada Fluminense. Duque de Caxias, Rio de Janeiro, Brasil.
} 
contradições se apresentam em toda a história da EPT no Brasil e a sua defesa, adesão e/ou comprometimento e definição através de políticas públicas ou de governo estão em constante mutação, influenciadas por diferentes agentes que emergem em dados momentos dessa linha do tempo.

Considerando as contribuições de Moura (2010), Ball (2011), Pires (2011) e Machado e Velten (2013), esse artigo apresenta os resultados de uma análise documental sobre a concepção de EPT no Brasil em documentos que fazem parte de uma história mais recente e que influenciaram e determinam algumas políticas públicas de ensino. É feito um estudo inicial sobre a EPT a partir de um resgate histórico de elaboração, aprovação e algumas alterações da Lei de Diretrizes e Bases da Educação/1996 (BRASIL, 1996) e o papel dos decretos nº 2.208/1997 (BRASIL, 1997) e $n^{\circ} 5.154 / 2004$ (BRASIL, 2004) no estabelecimento de algumas políticas de governo. Em seguida, são destacadas metas e estratégias que tratam da EPT no Plano Nacional de Educação (PNE) no decênio 2014-2024 (BRASIL, 2014). Na seção seguinte, são analisados os papéis e a contribuição da Conferência Nacional de Educação - CONAE 2010 para a definição dessas metas, a abordagem da temática Trabalho e Educação e a concepção de educação no Documento-Final da CONAE 2010 (CONAE, 2010) e no Documento-Referência da CONAE 2014 (CONAE, 2013). Por fim, é feita uma avaliação do tratamento dado à EPT nesse conjunto de documentos analisados e das perspectivas a partir da aprovação do novo PNE. No que tange aos procedimentos metodológicos adotados, priorizouse na análise dos documentos o enfoque de dois temas: a concepção de EPT e a relação entre trabalho e educação implícitos nos textos selecionados. A seleção desses temas converge para a consecução do objetivo de estudo proposto.

\section{Educação Profissional e Tecnológica na LDB/1996 e os desdobramentos nas últimas décadas}

Construída a partir de intensa participação do governo e da sociedade civil em discussões travadas desde a década de 1970, a LDB, sancionada em 1996 pelo presidente Fernando Henrique Cardoso (FHC), é um importante instrumento de estudo para o entendimento das diferentes concepções de EPT no Brasil nas últimas décadas.

O projeto de lei inicial para essa LDB/1996 foi delineado por Dermeval Saviani e apresentado à Câmara Federal em 1988 pelo deputado federal Octávio Elísio (PMDB-MG). O documento buscava incorporar os anseios educacionais de segmentos representativos da sociedade brasileira. Em dezembro de 1988, o texto apresentado pelo deputado Octávio Elísio foi relatado pelo também deputado 
Jorge Hage (PSDB-BA e depois PDT) após receber algumas emendas. Em meio a muitas negociações, o texto permaneceu na Câmara dos Deputados até 1993, quando foi enviado ao Senado. Em 1995, o senador Darcy Ribeiro (PDT-RJ), que já havia encaminhado ao Senado Federal um texto próprio para LDB no ano de 1992, apresentou um novo substitutivo, que trazia parte do texto inicial de 1992, algumas contribuições do projeto originalmente apresentado por Elísio em 1988 e outros pontos acordados com o governo de FHC. Esse substitutivo de Darcy Ribeiro seguiu o trâmite legal necessário e foi sancionado, sem vetos, pelo presidente em dezembro de 1996.

Segundo Shiroma, Moraes e Evangelista (2011, p. 43), a LDB, Lei no 9.394/1996, foi apresentada como uma lei moderna que teria como norte o século XXI: "Afirmando que o projeto Jorge Hage era arcaico, seu proponente tecia comentários laudatórios à lei, realçando sua flexibilidade, seu minimalismo, sua adequação às exigências do mundo moderno".

Essa versão inicial da LDB, sancionada em 20 de dezembro de 1996, tratava da EPT nos parágrafos $2^{\circ}$ e $4^{\circ}$ do artigo 36, quando definia as diretrizes do Ensino Médio e previa a possibilidade de "preparação para o trabalho". Destinou ainda um capítulo específico para a EPT: Capítulo III - Da Educação Profissional, quando definiu de forma simples e pouco direta os princípios para a educação profissional no Brasil, nos artigos 39 a 42. Apesar de possuir um capítulo específico na LDB, a EPT carecia ainda de muitas definições que não estavam presentes na lei. Tais definições para a EPT e outras mais necessárias à educação brasileira nos diferentes níveis de ensino, e que se apresentavam de forma imprecisa na LDB, foram determinadas de forma definitiva por meio de outras leis complementares ou de forma temporária/transitória através de decretos, portarias ministeriais ou resoluções desde o ano de publicação (1996) até os dias atuais.

Importante destacar que um projeto de lei deve seguir um caminho longo e ser apreciado e aprovado na Câmara e no Senado, além de ser sancionado pelo presidente da república. Estabelece-se, então, um longo processo de discussão e de travamento de disputas entre os diferentes atores participativos, o que tende a tornar o debate rico e de grande expressão dos anseios da comunidade. Já no caso dos decretos, estes seguem um caminho mais curto para a aprovação, reduzindo a discussão e enfraquecendo o envolvimento democrático da comunidade. Por fim, as portarias ministeriais e as resoluções são atos administrativos que trazem na sua concepção um mínimo caminho de discussão em um fórum mais reduzido. De modo lógico e sequencial, é possível afirmar que as portarias possuem fundamento de validade em decretos; estes encontram fundamento de validade 
nas leis; e todos necessitam ter fundamento de validade na Constituição Federal. Observam-se, ao longo da história, alguns casos em que os decretos, portarias e resoluções não foram utilizados como complementos, mas como "atalhos" para implementação de políticas de governo de forma imediata, facilitada e transitória.

No contexto da EPT, foi publicado o Decreto ${ }^{\circ} 2.208$ de 17/04/1997 (BRASIL, 1997), no qual o governo de FHC regulamentava o parágrafo $2^{\circ}$ do artigo 36 e os artigos 39 a 42 da Lei n $^{\circ}$ 9.394, de 20/12/1996 (BRASIL, 1996), ou seja, definia de forma direta e objetiva o que não estava claro no texto da LDB. Neste decreto, eram determinados os objetivos da educação profissional, as suas formas de articulação, seus níveis, diretrizes curriculares, formas de estruturação dos currículos e outros aspectos. Começaram a ser utilizadas as palavras "habilidades" e "competências", foram definidos os níveis da educação profissional (básico, técnico e tecnológico), a possibilidade de certificação por competências como forma de aproveitamento de saberes e feita a imposição de uma formação técnica apenas de forma concomitante ou subsequente ao Ensino Médio, extinguindo a possibilidade de formação técnica integrada. Por força de decreto, mas com poder de lei, a serviço de uma corrente e contrariando várias outras, determinaram-se várias e significativas mudanças na EPT do Brasil. Essa política de governo deixou claro seu compromisso com uma formação tecnicista ${ }^{1}$ voltada para o mercado de trabalho e flexível de acordo com os interesses econômicos, exterminando a possibilidade de uma formação mais humanística e unitária, através de cursos técnicos integrados ao Ensino Médio. O Brasil passava, nesse momento, por uma reestruturação articulada com as políticas ideológicas do neoliberalismo, conforme afirma Jessop (1994, p. 30 apud Ball, 2011, p. 23): "Em termos econômicos estritos, a estratégia neoliberal demanda mudanças na regulação (governo) dos setores público e privado. Para o setor público, isso envolve privatização, liberalização e uma imposição de critérios comerciais em algum setor estatal residual".

Para Machado e Velten (2013, p. 1115),

o Decreto $\mathrm{n}^{\circ} 2.208 / 97$ provocou o desaparelhamento e até o fechamento de muitas escolas e cursos técnicos públicos. Estimulou igualmente o surgimento de diferentes modelos de gestão estadual da educação profissional, processo reforçado por concepções de reforma gerencialista do Estado.

De acordo com Fidalgo e Machado (2000), o adjetivo "tecnicista" é usado para caracterizar ações educativas que priorizam o aprendizado de técnicas de forma sequencial. 
Os conceitos de competência profissional e habilidades, a organização por áreas profissionais, dentre outras diretrizes para a EPT, foram definidos na Resolução $n^{\circ}$ 04/1999 do Conselho Nacional de Educação (CNE) (BRASIL, 1999), que instituiu as Diretrizes Curriculares Nacionais para a Educação Profissional de Nível Técnico.

Em 2004, já no governo do então presidente Luiz Inácio Lula da Silva (Lula), ocorreu a publicação do Decreto $n^{\circ} 5.154$ de 23/07/2004 revogando o Decreto ${ }^{\circ}$ 2.208/1997, de modo a definir as políticas de governo para a EPT, aproveitando a pouca objetividade da LDB/1996, tal como no governo de FHC. Esse novo decreto redefiniu os níveis da educação profissional, suas premissas, as formas de articulação com o Ensino Médio (retornando à possibilidade de formação técnica integrada, além das concomitante e subsequente já disponíveis), certificações parciais e diplomas, dentre outros. Com essas mudanças, o governo Lula acena com a possibilidade de oferta de uma educação profissional integral ${ }^{2}$ mais voltada para uma concepção ampla de formação humana, mas, ainda assim, permite, também, a oferta do modelo de formação tecnicista e direcionada para o ingresso rápido do indivíduo no mercado de trabalho. Tal decisão surgiu como fruto de intensas discussões políticas e teóricas, conforme afirma Moura:

Ainda no final de 2002, no período de transição entre os governos FHC e Lula, retoma-se a discussão sobre a relação entre o EM e a EP no âmbito da equipe que elaborou a proposta educacional do novo governo. Em 2003, ocorreram seminários nacionais sobre o EM e sobre a EP, cujo cerne foi a relação entre eles. As discussões políticas e teóricas foram intensas e polêmicas, sendo que seu acúmulo se materializou no Decreto n. 5.154/2004, o qual aponta para a possibilidade de integração entre o EM e a EP, mas mantém as outras duas possibilidades de articulação previstas no Decreto n. 2.208/1997: as formas subsequente e concomitante. Essas múltiplas possibilidades constituem-se em bom indicador das mencionadas polêmicas (MOURA, 2010, p. 882).

Na Resolução n ${ }^{\circ}$ 01/2005 do CNE (BRASIL, 2005), as Diretrizes Curriculares Nacionais definidas para o Ensino Médio e para a Educação profissional Técnica de Nível Médio foram atualizadas. Definiram-se novas referências de carga horária mínima para a Educação Profissional Técnica de Nível Médio e atualizou-se a nomenclatura dos cursos e programas de Educação Profissional: "Educação Profissional de nível básico"

\footnotetext{
Integral vem de integralis, palavra que em latim significa inteiro. Uma formação integral é uma formação por inteiro com o objetivo de alcançar a omnilateralidade, ou seja, a formação completa (FIDALGO; MACHADO, 2000).
} 
passou a denominar-se "formação inicial e continuada de trabalhadores"; "Educação Profissional de nível técnico" passou a denominar-se "Educação Profissional Técnica de nível médio"; e "Educação Profissional de nível tecnológico" passou a denominar-se "Educação Profissional Tecnológica, de graduação e de pós-graduação".

Essas e algumas outras intervenções governamentais, após a LDB, redefiniram os rumos da EPT no Brasil a partir de decretos, portarias e resoluções que instituíram políticas de governo com pontos pouco discutidos amplamente e, em alguns casos, considerados bem contraditórios.

Com o objetivo de tornar lei grande parte das definições constantes no Decreto $n^{\circ} 5.154 / 04$ (BRASIL, 2004) e na Resolução $n^{\circ}$ 01/2005 do CNE (BRASIL, 2005), foi proposta, discutida e sancionada a Lei $\mathrm{n}^{\circ} 11.741$ de 16/07/2008 (BRASIL, 2008a) que alterou os artigos 37, 39, 41 e 42, revogou os parágrafos $2^{\circ}$ e $4^{\circ}$ do artigo 36 e o parágrafo único do artigo 41 da LDB, além de criar a seção IV-A - da Educação Profissional Técnica de Nível Médio. Trata-se de um marco importante para a Educação Profissional no Brasil, por dois motivos, em especial (dentre outros): pela Educação Profissional Técnica de Nível Médio ter passado a constar na Seção IV-A da LDB, dentro do Capítulo II, que trata da Educação Básica e do Título V - Dos Níveis e das Modalidades de Educação e Ensino; e pela LDB ter de fato incorporado definições claras e objetivas para a EPT, revogando o Decreto $n^{\circ} 5.154 / 2004$ que, na sua publicação, também já havia revogado o Decreto no 2.208/1997 (BRASIL, 1997).

A inclusão da Educação Profissional Técnica de Nível Médio na Seção IV-A do Capítulo II do Título V da LDB significa que, a partir de 16/07/2008, com a publicação da Lei ${ }^{\circ} 11.741$, a Educação Profissional Técnica de Nível Médio passou a ser considerada direito de todos cidadãos brasileiros, já que passou a ser considerada como parte da Educação Básica, definida na Constituição Federal e na própria LDB como garantida pelo Estado com educação pública:

Art. $4^{\circ} \mathrm{O}$ dever do Estado com educação escolar pública será efetivado mediante a garantia de:

I - Educação básica obrigatória e gratuita dos 4 (quatro) aos

17 (dezessete) anos de idade, organizada da seguinte forma:

a) Pré-escola;

b) Ensino Fundamental; 
c) Ensino Médio;<smiles></smiles>

IV - Acesso público e gratuito aos Ensinos Fundamental e Médio para todos os que não os concluíram na idade própria;

VII - oferta de educação escolar regular para jovens e adultos, com características e modalidades adequadas às suas necessidades e disponibilidades, garantindo-se aos que forem trabalhadores as condições de acesso e permanência na escola (BRASIL, 1996).

Essas definições mais criteriosas para a EPT na LDB, revogando o Decreto ${ }^{\circ}$ 5.154/2004 (BRASIL, 2004), também mostraram grande avanço na discussão e mobilização por parte da sociedade civil e políticos, o que legitimou e transformou uma política transitória de governo em política permanente de Estado. Reforçou a política nacional adotada nos anos 2000 de ampliação da Rede Federal de EPT, na qual o Governo Federal criou centenas de unidades de ensino técnico e tecnológico e transformou os Centros Federais de Educação Tecnológica (CEFET) em Institutos Federais de Educação, Ciência e Tecnologia (IF), criando milhares de vagas para cursos técnicos de nível médio, cursos superiores de tecnologia e licenciaturas, um contraste com a década de 1990, quando as políticas públicas apontavam para um esvaziamento da responsabilidade do Estado na oferta de EPT.

As mudanças destacadas na LDB garantiram uma maior estabilidade e possibilidade de planejamento em longo prazo a partir das políticas de Estado definidas na lei, mas continuam sendo alvo de críticas de alguns setores da sociedade e de grande parte da comunidade acadêmica, pelo fato de permitir outras possibilidades de formação que não apenas a integral a partir dos Cursos Técnicos Integrados. Esses grupos entendem que estaria sendo incentivada uma formação mais tecnicista, imediata e simplista para atender apenas às necessidades do mercado de trabalho ao permitir a oferta de cursos técnicos concomitantes.

Mesmo reconhecendo a importância da estrutura e da organização econômica de uma nação, não se pode pensar a formação do trabalhador apenas para atender a esta estrutura. Acredita-se que a oferta de uma educação integrada traria, dentre outras, a possibilidade de uma formação mais ampla, mais humana (PIRES, 2011, p. 202-3). 
Já em relação aos cursos subsequentes, existem outros entendimentos, dentre os quais se faz importante destacar o apresentado por Moura:

Compreende-se que a forma subsequente - cursos técnicos de nível médio destinados a quem já concluiu o EM - justifica-se pelo fato de que há muitos jovens e adultos que concluíram o EM propedêutico de baixa qualidade e que não vão para o $\mathrm{ES}$, nem têm condições de inserção em atividades complexas, entre as ocupações de nível médio. Assim, em razão dessa distorção, que é fruto da incapacidade do Estado brasileiro de garantir educação básica com qualidade para todos, os cursos técnicos subsequentes podem contribuir para melhorar as condições de inserção social, política, cultural e econômica desses brasileiros (MOURA, 2010, p. 882).

Observa-se que, mesmo com significativos avanços no legislativo e executivo em torno da EPT, muitas são as questões ainda em discussão nas diferentes esferas e setores da sociedade, movimento típico de uma nação democrática de direito. Recentemente em discussão, o PNE 2014-2024³ tem sido tema de grandes embates e contradições, com desdobramentos em fóruns e reuniões. A seguir, serão apresentadas algumas questões sobre esse plano no contexto da EPT.

\section{Educação Profissional e Tecnológica no PNE 2014-2024}

Proposto pelo executivo no Projeto de Lei no 8.035/2010 (BRASIL, 2010a), o PNE previsto inicialmente para o decênio 2011-2020 tramitou por quatro anos na Câmara dos Deputados e no Senado Federal, e contou com mais de 2.900 emendas após intensas discussões, sendo sancionado na Lei $\mathrm{n}^{\circ} 13.005$ de 25/06/2014 (BRASIL, 2014) para o decênio 2014-2024. Está organizado com o estabelecimento de 20 metas associadas a estratégias para o crescimento e o desenvolvimento da educação brasileira no decênio 2014-2024 e, de maneira implícita, trata das políticas de governo para um período de 10 anos, dando continuidade (ou não) ao PNE 2001-2010 (BRASIL, 2001), que definiu os objetivos para a educação nessa década inicial.

Devido à sua importância, abrangência e caráter de longo prazo de duração e execução, provocou discussões calorosas entres os representantes dos partidos políticos na Câmara e no Senado, bem como na sociedade civil organizada. Alguns pontos que travavam a pauta às vezes se confundiam entre o desejo

3 Inicialmente previsto para o decênio 2011-2020, o projeto de lei desse PNE levou cerca de quatro anos em discussão na Câmara dos Deputados e Senado Federal até sua aprovação, o que acarretou na mudança de vigência para 2014-2024. 
de uma educação de melhor qualidade e o receio do compromisso que deveria ser assumido por dez anos, o que perpassa vários mandatos políticos no período. Confundem-se os interesses por uma educação melhor e o receio da obrigatoriedade de cumprir um compromisso que exige, na maioria dos casos, muito investimento, vontade política e desgastes com diferentes atores sociais. Pesam as discussões para um planejamento de médio prazo em um país tão acostumado a propor apenas políticas de governo de curto prazo de execução que, na maioria das vezes, são abandonadas ou desfeitas no governo seguinte. Trata-se de um "exercício" diferente e necessário no cenário da educação brasileira. Proposta semelhante, aliás, da CONAE 2014 (CONAE, 2013), conforme será detalhado posteriormente.

Mesmo antes de sua aprovação, quando ainda tramitava na Câmara dos Deputados e no Senado Federal, o PNE já orientava algumas políticas de governo e servia como norte para o estabelecimento de discussões e embates. Algumas ações de expansão da oferta de ensino público, criação de programas para formação de professores, ampliação de vagas para formação de técnicos em programas de ensino público a distância ou através do Programa Nacional de Acesso ao Ensino Técnico e Emprego (PRONATEC) são exemplos de políticas de governo que foram implantadas em sintonia com o novo PNE, mesmo antes de sua aprovação e publicação da Lei no 13.005/2014 (BRASIL, 2014).

O PNE 2014-2024 (BRASIL, 2014) está estruturado em 20 metas e cada uma delas possui algumas estratégias associadas de modo a contribuir para a sua efetiva realização. A EPT está atendida diretamente nas metas 10 e 11 .

A meta 10 trata da oferta de educação profissional para jovens e adultos e define: "Oferecer, no mínimo, 25\% (vinte e cinco por cento) das matrículas de educação de jovens e adultos, nos Ensinos Fundamental e Médio, na forma integrada à educação profissional" (BRASIL, 2014).

Em consonância com essa meta, o Governo Federal tem ampliado a oferta de Cursos Técnicos Integrados com o Ensino Médio para Jovens e Adultos através do Programa Nacional de Integração da Educação Profissional com a Educação Básica na Modalidade de Jovens e Adultos (PROEJA). Os IF, por exemplo, têm na essência de sua criação o objetivo de "ministrar educação profissional técnica de nível médio, prioritariamente na forma de cursos integrados, para os concluintes do Ensino Fundamental e para o público da educação de jovens e adultos ${ }^{4}$ " (BRASIL, 2008b).

\footnotetext{
4 Negrito dos autores.
} 
Na meta 11, é definido o compromisso de triplicar o número de matrículas da Educação Profissional Técnica de nível médio, assegurando a qualidade da oferta e pelo menos $50 \%$ (cinquenta por cento) da expansão no segmento público.

\section{Assim como na meta 10, percebe-se que o Governo já estava trabalhando no sentido de tentar cumprir a meta 11, mesmo antes da aprovação do PNE 2014-2024. Programas como o PRONATEC e a expansão da rede federal de educação profissional e tecnológica com a criação de novos campi dos IF têm contribuído consideravelmente para o aumento no número de matrículas na educação profissional técnica de nível médio.}

\section{A EPT é ainda tratada como estratégia de outras metas do PNE, como é possível notar nas estratégias 3.7, 3.10, 8.4, 10.8, 11.4, 11.6 e 12.25. De forma indireta, mas com influência imediata, estão também as metas que tratam da formação e valorização dos professores, contemplando, nesse caso, as metas 15, 16, 17,18 e $19^{6}$.}

\footnotetext{
5 A estratégia 3.7 trata do fomento à expansão das matrículas gratuitas de Ensino Médio integrado à educação profissional, observando-se as peculiaridades das populações do campo, das comunidades indígenas e quilombolas e das pessoas com deficiência; já a estratégia 3.10 trata do fomento aos programas de educação e de cultura para a população urbana e do campo de jovens, na faixa etária de 15 a 17 anos, e de adultos, com qualificação social e profissional para aqueles que estejam fora da escola e com defasagem no fluxo escolar; a estratégia 8.4 define a expansão da oferta gratuita de educação profissional técnica por parte das entidades privadas de serviço social e de formação profissional vinculadas ao sistema sindical, de forma concomitante ao ensino ofertado na rede escolar pública, para os segmentos populacionais considerados. Na estratégia 10.8, define-se o fomento à oferta pública de formação inicial e continuada para trabalhadores e trabalhadoras articulada à educação de jovens e adultos, em regime de colaboração e com apoio de entidades privadas de formação profissional vinculadas ao sistema sindical e de entidades sem fins lucrativos de atendimento à pessoa com deficiência, com atuação exclusiva na modalidade; a estratégia 11.4 trata do estímulo a expansão do estágio na educação profissional técnica de nível médio e do Ensino Médio regular, preservando-se seu caráter pedagógico integrado ao itinerário formativo do aluno, visando à formação de qualificações próprias da atividade profissional, à contextualização curricular e ao desenvolvimento da juventude. Na estratégia 11.6, define-se a ampliação da oferta de matrículas gratuitas de educação profissional técnica de nível médio pelas entidades privadas de formação profissional vinculadas ao sistema sindical e entidades sem fins lucrativos de atendimento à pessoa com deficiência, com atuação exclusiva na modalidade; e, por fim, na 12.2, é definida a ampliação da oferta de vagas na educação superior, por meio da expansão e interiorização da rede federal de educação superior, da Rede Federal de Educação Profissional, Científica e Tecnológica e do sistema Universidade Aberta do Brasil, considerando a densidade populacional, a oferta de vagas públicas em relação à população na idade de referência e observadas as características regionais das micro e mesorregiões definidas pela Fundação Instituto Brasileiro de Geografia e Estatística - IBGE, uniformizando a expansão no território nacional.

6 A meta 15 define a construção de uma política nacional de formação dos profissionais da educação, no prazo de um ano da vigência do PNE 2014-2024, assegurado que todos os professores e as professoras da Educação Básica possuam formação específica de nível superior, obtida em curso de licenciatura na área de conhecimento em que atuam. A meta 16 define o compromisso de formar, em nível de pós-graduação, 50\% dos professores da educação básica, até o último ano de vigência do PNE, e garantir a todos(as) os(as) profissionais da educação básica formação continuada em sua área de atuação, considerando as necessidades, demandas e contextualizações dos sistemas de ensino. Já a meta 17 trata da valorização dos profissionais do magistério das redes públicas de educação básica de forma a equiparar seu rendimento médio ao dos demais profissionais com escolaridade equivalente, até o final do sexto ano de vigência do PNE. A meta 18 assegura, no prazo de dois anos, a existência de planos de Carreira para os profissionais da Educação Básica e Superior pública de todos os sistemas de ensino e, para o plano de Carreira dos profissionais da educação básica pública, tomar como referência o piso salarial nacional profissional, definido em lei federal, nos termos do inciso VIII do art. 206 da Constituição Federal. A meta 19 assegura condições, no prazo de dois anos, para a efetivação da gestão democrática da educação, associada a critérios técnicos de mérito e desempenho e à consulta pública à comunidade escolar, no âmbito das escolas públicas, prevendo recursos e apoio técnico da União.
} 
Alguns autores questionam o PNE por tratar de forma direta a EPT apenas em duas metas, ao passo que o PNE 2001-2010 (BRASIL, 2001) destinava quinze. Apesar de as metas do PNE 2014-2024 (BRASIL, 2014) serem tratadas em uma perspectiva multidimensional, de fato são poucas as metas e estratégias que possuem como finalidade aEPT. Imprescindível destacar que o número reduzido não deve ser entendido como uma "baixa importância dada a EPT". Isso porque a meta 11 estabelece uma tarefa consideravelmente desafiadora: triplicar as matrículas na educação profissional técnica de nível médio assegurando a qualidade de oferta. Deve-se considerar que, na década de 1990, a rede federal de educação profissional e tecnológica ficou retraída e "impedida de crescer" por força de decretos e portarias que implantaram uma política de Estado Mínimo na educação profissional e tecnológica. Nos anos 2000 , foi retomada a ampliação de oferta dessa modalidade de ensino e a rede federal de educação profissional e tecnológica mais que triplicou o número de unidades ou campi. Dessa forma, pretender a triplicação do número de matrículas em uma rede que já foi consideravelmente ampliada conduz a um grande desafio que envolve muita vontade política, investimento e ousadia para sua concretização. Trata-se de uma meta que poderia ter sido desdobrada em muitas outras, caso fosse esse o formato do PNE, tais como: ampliação da rede federal de educação profissional e tecnológica, aumento do número de professores para a formação técnica de nível médio, aumento do montante de financiamento para essa modalidade de ensino, destinação de maior volume de recursos para as políticas de permanência de estudantes, dentre outras.

Mais importante do que o número de metas é o que as metas contemplam para a EPT. Identifica-se um grande desafio para a EPT de acordo com as definições do PNE 2014-2024 (BRASIL, 2014) e, certamente, se essas metas forem cumpridas, o país dará um grande salto na oferta de educação profissional.

O PNE 2014-2024 (BRASIL, 2014) teve grande influência da CONAE 2010, que serviu como base de discussão e construção do planejamento da educação nacional a médio prazo. A seguir, serão apresentadas algumas contribuições da CONAE 2010 para construção do PNE 2014-2024 e os apontamentos do Documento-Referência da CONAE 2014 (CONAE, 2013).

\section{Educação Profissional e Tecnológica no Documento-Final da CONAE 2010 e no Documento- Referência da CONAE 2014}

ACONAE é um espaço de deliberação e participação coletiva, envolvendo diferentes segmentos, setores e profissionais interessados na construção de políticas públicas de Estado. É precedida por conferências preparatórias e livres, municipais e/ou 
intermunicipais, do Distrito Federal e estaduais de educação. Essas conferências prévias discutem um Documento-Referência elaborado pelo Fórum Nacional de Educação (FNE) - criado pela Portaria ${ }^{\circ}$ 1.407/2010 (BRASIL, 2010b) e alterado pela Portaria no 502/2012 do Ministério da Educação (MEC) (BRASIL, 2012).

As propostas resultantes das conferências prévias devem ser sintetizadas em emendas e apresentadas por unidade da Federação. Essas emendas compõem os relatórios dos fóruns estaduais de educação no Sistema de Relatoria do FNE e são objeto de análise da Comissão Especial de Monitoramento e Sistematização. Após essa análise, as emendas são conferidas e aprovadas (ou não), pelos membros do FNE, compondo o Documento-Base da CONAE. Esse Documento-Base é estruturado em dois volumes:

- Volume I - com Bloco I (emendas aprovadas em cinco ou mais Estados, que o FNE recomenda a incorporação) e com Bloco II (emendas que o FNE não recomenda a incorporação).

- Volume II - com o Bloco III (emendas passíveis de destaque aprovadas em menos de cinco Estados).

Esse Documento-Base é objeto de discussão durante a CONAE, e o resultado dessa discussão dá origem ao Documento-Final da CONAE. A seguir, é apresentado o fluxo de organização e de realização da CONAE, conforme Figura 1.

\section{Organização e Realização da CONAE}

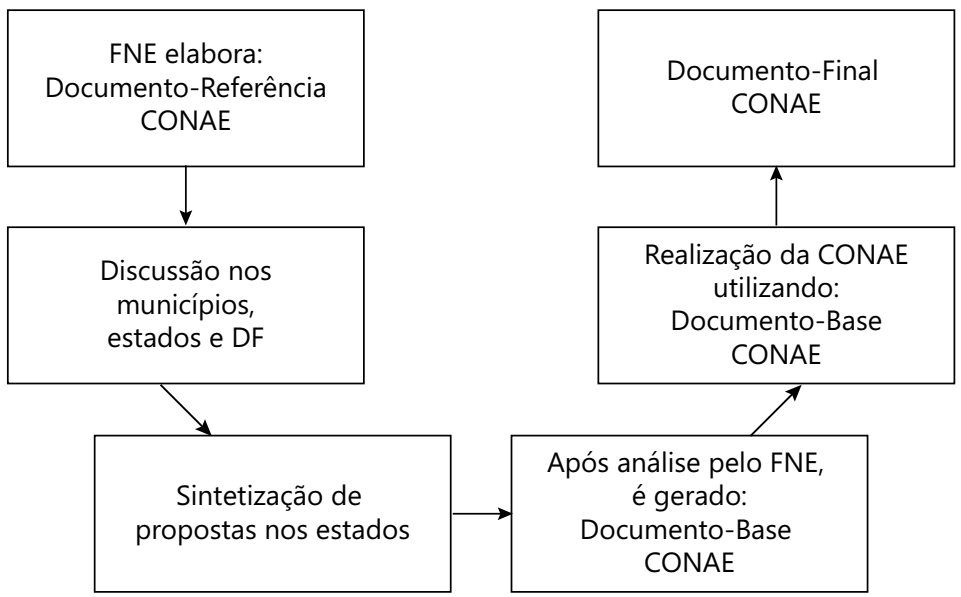

Fonte: Elaborada pelos autores (2014).

Figura 1. Fluxo de organização e de realização da CONAE. 
Seguindo esse percurso de trabalhos e discussões envolvendo diversas representações, a CONAE 2010 aconteceu na perspectiva de contribuir com a formulação e materialização de políticas de Estado na Educação, inclusive para a construção do PNE 2011-2020, conforme previsão no Documento-Final de 2010:

Espera-se, portanto, que este Documento Final contribua com o esforço coletivo em prol da educação brasileira, tendo as deliberações da Conae como horizonte para a formulação e materialização de políticas de Estado na educação, sobretudo, para a construção do novo Plano Nacional de Educação, período 2011-2020 (CONAE, 2010, p. 11).

Tinha um objetivo claro de mobilização social e utilizou a temática "CONAE: Construindo o Sistema Nacional Articulado: O PNE, Diretrizes e Estratégias de Ação". Seus principais objetivos foram:

e) construir o Sistema Nacional de Educação (SNE) [...]

f) promover de forma permanente o debate nacional, estimulando a mobilização em torno da qualidade e valorização da educação básica, superior e das modalidades de educação, em geral, [...]

g) garantir que os acordos e consensos produzidos na Conae redundem em políticas públicas de educação, [...]

h) propiciar condições para que as referidas políticas educacionais, concebidas e efetivadas de forma articulada entre os sistemas de ensino, promovam: o direito do/da estudante à formação integral com qualidade; o reconhecimento e valorização à diversidade; a definição de parâmetros e diretrizes para a qualificação dos/das profissionais da educação; o estabelecimento de condições salariais e profissionais adequadas e necessárias para o trabalho dos/das docentes e funcionários/as; a educação inclusiva; a gestão democrática e o desenvolvimento social; o regime de colaboração, de forma articulada, em todo o País; o financiamento, o acompanhamento e o controle social da educação; e a instituição de uma política nacional de avaliação no contexto de efetivação do SNE;

i) indicar, para o conjunto das políticas educacionais implantadas de forma articulada entre os sistemas de ensino, que seus fundamentos estão alicerçados 
na garantia da universalização e da qualidade social da educação em todos os seus níveis e modalidades, bem como da democratização de sua gestão (CONAE, 2010, p. 14-15).

Os documentos Referência e Final foram organizados em seis eixos temáticos: I-Papel do Estado na Garantia do Direito à Educação de Qualidade: Organização e Regulação da Educação Nacional; II - Qualidade da Educação, Gestão Democrática e Avaliação; III - Democratização do Acesso, Permanência e Sucesso Escolar; IV - Formação e Valorização dos Trabalhadores em Educação; V-Financiamento da Educação e Controle Social; VI - Justiça Social, Educação e Trabalho: Inclusão, Diversidade e Igualdade.

No Documento-Final da CONAE, apresentado em abril de 2010, a relação entre trabalho e educação foi contemplada no eixo VI "Justiça social, educação e trabalho: inclusão, diversidade e igualdade". Segundo Pires (2011, p. 201), "a junção destes temas em um único eixo objetivou que as questões ligadas à justiça social, ao trabalho e à diversidade estejam presentes nas diversas instituições educativas e em todos os níveis e modalidades de educação". Percebe-se um movimento de integração da educação com o trabalho na defesa da inclusão, diversidade e igualdade, uma proposta de educação na perspectiva do trabalho como princípio educativo.

Esse eixo propõe uma sociedade que articule justiça social, trabalho e educação. Pires (2011, p. 202) afirma que "no eixo VI a 'formação cidadã e profissional' se resumiu a apenas seis alíneas, enquanto outras possuem trinta e duas alíneas". Ainda segundo a autora, dos seis itens que tratam da educação profissional, quatro deles explicitam a necessidade de atendimento ao mercado e aos arranjos produtivos.

Pires (2011, p. 203) cita as alíneas "e" e "f" do eixo III, "Democratização do acesso, permanência e sucesso escolar", afirmando que nesses itens existe a preocupação com a formação mais humana do trabalhador. No entanto, chama atenção para ambiguidades nessas alíneas, conforme apontado por Moura (2010).

Segundo Moura (2010), aparece na alínea "e" uma disputa em torno de projetos societários distintos: ao mesmo tempo que se propõe o rompimento do dualismo estrutural entre o Ensino Médio e a educação profissional, essa última poderá continuar sendo ofertada pela iniciativa privada, o que significa a não necessidade de rompimento com o dualismo estrutural apontado. Já na alínea "f", ao mesmo tempo em que se define pela expansão de uma educação pública profissional de qualidade, entendida na perspectiva do trabalho, como princípio educativo, 
afirma-se que deverá atender às demandas produtivas e sociais locais, regionais e nacionais com financiamento público permanente.

De forma distinta ao exposto por Moura (2010), entendemos que, na alínea "e", é apresentada uma constatação da existência de um dualismo estrutural entre o Ensino Médio e a educação pública profissional, mas aponta-se para a necessidade de compreensão do Ensino Médio na concepção de escola unitária e de escola politécnica, buscando garantir o Ensino Médio integrado à educação profissional, apesar da possibilidade legal de ainda ofertar cursos técnicos concomitantes e subsequentes. Já na alínea " $\mathrm{f}$ " desse mesmo eixo, é ratificada a necessidade de oferta de nível médio integrado ao profissional, bem como cursos superiores de tecnologia, bacharelados e licenciaturas. Essa alínea deixa clara a posição em defesa de uma educação pública profissional entendida na perspectiva do trabalho como princípio educativo, que também deve atender às demandas produtivas e sociais locais, regionais e nacionais. Apesar da previsão de consonância com as demandas produtivas e sociais, destaca-se a prioridade por uma educação na perspectiva do trabalho como princípio educativo.

O Documento-Final da CONAE 2010 (CONAE, 2010), apesar de não ser o texto base do projeto de lei do PNE 2011-2020, contribuiu em âmbito nacional com discussões que asseguraram a articulação entre os entes federados e os diversos setores da sociedade civil organizada ou não.

Dando andamento no planejamento de realização de outras conferências nacionais, a CONAE 2014 surgiu com a temática central: “O PNE na Articulação do Sistema Nacional de Educação: Participação Popular, Cooperação Federativa e Regime de Colaboração". O CNE elaborou, então, um Documento-Referência com o intuito de:

Subsidiar as discussões das diferentes conferências, servindo como parâmetro para os debates locais, municipais, estaduais e regionais, cujos resultados deverão se traduzir em proposições e deliberações, com as posições políticas e pedagógicas dos diferentes grupos (CONAE, 2013, p. 11).

O objetivo geral definido pelo FNE para essa conferência foi "propor a Política Nacional de Educação, indicando responsabilidades, corresponsabilidades, atribuições concorrentes, complementares e colaborativas entre os entes federados e os sistemas de ensino" (CONAE, 2013, p. 11). 
Como objetivos específicos foram definidos pelo FNE:

1. Acompanhar e avaliar as deliberações da Conferência Nacional de Educação/2010, verificando seu impacto e procedendo às atualizações necessárias para a elaboração da Política Nacional de Educação.

2. Avaliar a tramitação e a implementação do PNE na articulação do Sistema Nacional de Educação (SNE) e no desenvolvimento das políticas públicas educacionais (CONAE, 2013, p. 11).

Percebe-se, nessa definição, a intenção de dar continuidade aos trabalhos desenvolvidos na CONAE 2010, bem como avaliar o andamento do projeto de lei do PNE e das ações para garantir a sua aceitação e aplicação, mesmo sem a conclusão do trâmite legal para aprovação.

Alguns questionamentos podem surgir acerca de discutir um projeto de lei que ainda não havia sido sancionado, mas é possível identificar outras intenções nessa CONAE 2014 para além das mencionadas no Documento-Referência. Identifica-se uma estratégia de complementar as discussões da CONAE 2010 e do PNE 2011-2020, já que nesses documentos propõem-se metas ou necessidades e quais estratégias deveriam ser utilizadas, mas não são mencionados os atores desse processo e suas responsabilidades. O Documento-Referência da CONAE 2014 (CONAE, 2013) traz então responsabilidades, corresponsabilidades, atribuições concorrentes, complementares e colaborativas entre os entes federados (União, estados, Distrito Federal e municípios). Verifica-se uma tentativa de "organizar" o "Sistema Nacional de Educação" em um "regime de colaboração" entre os entes federados. Para Machado e Velten (2013, p. 1119),

O tema da II Conae mostra-se, portanto, muito oportuno, pois a indicação de responsabilidades, corresponsabilidades, atribuições concorrentes, complementares e colaborativas entre os entes federados e os sistemas de ensino são fundamentais à consolidação da política nacional de educação profissional e tecnológica e de um Sistema Nacional de Educação realmente integrado.

São propostos sete eixos centrais nesse documento: Eixo I - O PNE e o Sistema Nacional de Educação: organização e regulação; Eixo II - Educação e Diversidade: justiça social, inclusão e direitos humanos; Eixo III - Educação, Trabalho e Desenvolvimento Sustentável: cultura, ciência, tecnologia, saúde, meio ambiente; Eixo IV - Qualidade da Educação: democratização do acesso, permanência, avaliação, condições de participação e aprendizagem; Eixo V - Gestão 
Democrática, Participação Popular e Controle Social; Eixo VI - Valorização dos Profissionais da Educação: formação, remuneração, carreira e condições de trabalho; Eixo VII - Financiamento da Educação: gestão, transparência e controle social dos recursos.

Após cada eixo temático é apresentado um quadro com proposições e estratégias,

indicando as responsabilidades, corresponsabilidades, atribuições concorrentes, complementares e colaborativas entre os entes federados (União, estados, DF e municípios), tendo por princípios a garantia da participação popular, a cooperação federativa e o regime de colaboração. Espera-se que essas indicações contribuam para o planejamento e organicidades das políticas, especialmente para a elaboração, acompanhamento e avaliação dos planos de educação pelos entes federados (CONAE, 2013, p.12).

Aparenta ser essa uma tentativa de fazer uma convocação de todos os entes federados para suas responsabilidades no cumprimento das proposições e estratégias definidas que, em grande maioria, estavam em consonância com o PNE 2011-2020 então em tramitação.

Assim como no Documento-Final da CONAE 2010 (CONAE, 2010), no texto do Documento-Referência da CONAE 2014 (CONAE, 2013) é possível observar que a EPT não é abordada apenas em um eixo. O maior número de proposições e estratégias se encontra nos eixos III e IV, mas outras referentes a EPT também são tratadas nos eixos I, V, VI e VII.

A temática Trabalho e Educação é proposta com maior ênfase no Eixo III - Educação, Trabalho e Desenvolvimento Sustentável: Cultura, Ciência, Tecnologia, Saúde, Meio Ambiente. Defende-se a educação como uma prática social cada vez mais ampla. Também é apresentada uma constatação sobre as transformações econômicas no cenário internacional e no Brasil, desde os anos 1980, sendo importante destacar:

177. As transformações econômicas e políticas no cenário internacional e no Brasil, desde os anos 1980, decorrentes, em grande parte, da reestruturação produtiva, da mundialização do capital e da revolução tecnológica, implicam processos de regulação que acarretam mudanças no papel e na forma de atuação do Estado, bem como nas políticas educacionais, que passaram a se orientar, cada vez mais, pela lógica do mercado e da competição. Esse modo de regulação se contrapôs ao 
ideário de constituição de um estado democrático de direito, no qual o trabalho, a educação, a cultura, a ciência e a tecnologia constituiriam fatores de desenvolvimento econômico e social, inclusão, melhoria da qualidade de vida, desenvolvimento sustentável, requisitos para a superação dos mecanismos que, historicamente, mantêm as desigualdades (CONAE, 2013, p. 40).

O documento trata das transformações econômico-produtivas, sobretudo em razão das mudanças e inovações tecnológicas e dos novos modos de ação dos Estados e dos organismos multilaterais nas economias cada vez mais globalizadas. Afirma que foram se ampliando as demandas por formação de trabalhadores, considerando-se os novos perfis profissionais e a necessidade do desenvolvimento de novas habilidades, o que trouxe implicações para as instituições formativas, acadêmicas e profissionais.

Importante observar a constatação de que as políticas públicas e, sobretudo, as políticas de Educação, Trabalho, Ciência e Tecnologia passaram a considerar tais mudanças na definição de seus respectivos programas, planos e ações.

No parágrafo 179 , o texto menciona a necessidade de melhorar a qualidade de vida da população e de priorizar a qualidade de nossas escolas, e destaca a importância do Estado e dos governos no crescimento da renda, na redução das desigualdades, na garantia de direitos sociais e humanos e na formulação e implantação de políticas públicas que possam contribuir para mudanças sociais mais efetivas, tendo em vista a formação para o exercício da cidadania e a ampliação dos mecanismos de equalização das oportunidades de educação, trabalho, saúde e lazer.

O Documento-Referência da CONAE 2014 (CONAE, 2013) apresenta, ainda, uma conclusão importante no parágrafo 186 , tratando da formação de profissionais críticos e autônomos, a partir de uma concepção ampla de trabalho.

186. A articulação entre trabalho, educação e desenvolvimento sustentável implica avançar nas concepções e nas políticas setoriais e intersetoriais, visando:

a) a partir de uma concepção ampla de trabalho, formar profissionais capazes de atuar crítica e autonomamente, no enfrentamento da desigualdade social e diferentes formas de exclusão, do trabalho precário, da destruição do meio ambiente e da falta de qualidade de vida da população; 
b) reconhecer e garantir as formas de produção e o desenvolvimento sustentável dos povos indígenas e comunidades tradicionais;

c) reconhecer e valorizar a sustentabilidade socioambiental e a soberania alimentar;

d) promover ações articuladas para a garantia do direito à educação ao longo da vida;

e) promover maior articulação entre as políticas de Educação Básica, Superior, Pós-Graduação, Pesquisa, Ciência, Tecnologia, Cultura, Desporto, Saúde e Meio Ambiente (CONAE, 2013, p. 41-42).

Percebe-se claramente nessa passagem a articulação da educação e do trabalho ao desenvolvimento sustentável. Ao longo do texto, a temática Trabalho e Educação é abordada em associação direta com a tecnologia, o meio ambiente e a saúde.

Importante ainda destacar que o Documento-Referência não trata de forma clara da formação técnica integrada ao Ensino Médio no preâmbulo textual. Essa possibilidade de formação é tratada apenas nas metas/estratégias quando na abordagem da formação técnica de nível médio regular ou para jovens e adultos (PROEJA). Mas também não se estabelece claramente a defesa de uma formação tecnicista que atenda apenas ao setor produtivo, como ocorreu em alguns trechos do Documento-Final CONAE 2010 (CONAE, 2010). Pelo contrário, o texto proposto para o início dos debates da CONAE 2014 (CONAE, 2013) dispõe de uma defesa clara à formação unitária, humanística e emancipatória, mas não condiciona a formação técnica apenas à modalidade integrada ao Ensino Médio, mesmo porque a LDB prevê as formações na modalidade concomitante e subsequente, conforme exposto anteriormente.

\section{Considerações Finais}

As análises empreendidas nesse artigo descreveram de forma sucinta as transformações ocorridas na EPT no Brasil nos últimos anos, sobretudo a partir da LDB/1996. Verificaram-se alguns momentos de tensão e disputas que se sucederam à publicação da LDB e que, em movimento constante, teve a participação de diversos atores sociais e políticos até os dias atuais.

Foram analisadas algumas Políticas de Governo e outras de Estado que se sucederam em meio a disputas e diferentes concepções, com destaque para as alterações na 
LDB/1996 que atualmente contempla três possibilidades de formação técnica de nível médio: concomitante, subsequente ou integrada, comprovando a complexidade dos embates entre academia, sociedade civil e setor produtivo. Prevaleceu a política de atender a todos os atores sem marcar uma posição clara e precisa quanto à concepção do Estado acerca da relação entre trabalho e educação na educação profissional.

Alguns elementos e políticas de governo apontam para a oferta da formação técnica integrada ao Ensino Médio como prioritária, mas, ao possibilitar outros modos de oferta, sinaliza o seu compromisso muito forte ainda com o setor produtivo e uma formação tecnicista direcionada às demandas do mercado de trabalho.

Mesmo antes da publicação da Lei no 13.005/2014 (BRASIL, 2014), foi possível observar que o projeto de lei do PNE 2011-2020 (BRASIL, 2010a) já era utilizado como referência para o estabelecimento de políticas de governo em busca do atendimento total ou parcial das metas nele estabelecidas. Nesse contexto, foi atribuída uma enorme importância subjetiva à CONAE, pelo seu papel articulador e balizador na construção das políticas educacionais.

Cabe à sociedade permanecer no movimento de questionar, contribuir e participar dos diferentes encontros, conferências e reuniões, como tem sido nos diversos mecanismos de participação, dentre eles as Conferências Nacionais de Educação. Algumas vezes foi abordado nesse artigo que as definições de políticas para a educação estão diretamente ligadas aos movimentos e participações da sociedade civil e comunidades acadêmicas nas discussões. Somente com a participação de todos - entes federativos, comunidade acadêmica e sociedade civil - é possível dar vida a um desejado Sistema Nacional de Educação em regime de colaboração no qual a concepção de EPT esteja mais direcionada para a formação omnilateral ao vislumbrar as possibilidades do desenvolvimento integral dos indivíduos tendo a emancipação humana como horizonte. 


\section{Technical Vocational Education and Training: analysis and perspectives from LDB/1996 to CONAE 2014}

\section{Abstract}

This article analyzes the conception of Technical Vocational Education and Training (TVET) in Brazil on recent documents of great importance in the definitions of public policies for education. A documentary analysis is performed comprising of the Law of Guidelines and Bases of Education (LDB), of Law 9,394/1996, of decrees 2,208/1997 and 5,154/2004, of Law 13,005/2014 that comes from the National Education Plan (PNE) between 2014 and 2024 and of the End-Document and Reference-Document from the National Conferences on Education (CONAE) 2010 and 2014. Were found and shown in these documents some evidence of the use of different conceptions of TVET and identified a great importance given to the CONAE's in the articulation and construction of educational policies and the current PNE.

Keywords: Technical Vocational Education and Training. PNE. CONAE. Work and education.

\section{Educación profesional y tecnológica: análisis y perspectivas de la LDB/1996 a la CONAE 2014}

\section{Resumen}

Este artículo tiene como objetivo analizar el concepto de Educación Profesional y Tecnológica (EPT) en Brasil considerando los recientes documentos de gran importancia en la definición de las políticas públicas de educación. Un análisis documental se efectúa en la Ley de Directrices y Bases de la Educación (LDB) - Ley no. 9394/1996, en los decretos 2.208/1997 y 5.154/2004, en la Ley $n^{\circ}$. 13.005/2014 que se ocupa del Plan Nacional de Educación (PNE) en el decenio 2014-2024 y en el Documento-Final $y$ en el Documento-Referencia de las Conferencias Nacionales de Educación (CONAE) en 2010 y 2014. Fueron encontrados y se destaca en estos documentos cierta evidencia de uso de las diferentes concepciones de EPT y se identificó una gran importancia dada la CONAES, la articulación y la construcción de las políticas educativas y el PNE actual.

Palabras clave: Educación Profesional y Tecnológica. PNE. CONAE. Trabajo y educación. 


\section{Referências}

BALL, S. J. Políticas educacionais: questões e dilemas. São Paulo: Cortez, 2011.

BRASIL. Conselho Nacional de Educação. Câmara de Educação Básica. Resolução $\mathrm{n}^{\circ}$ 1, de 03 de fevereiro de 2005. Atualiza as Diretrizes Curriculares Nacionais definidas pelo Conselho Nacional de Educação para o Ensino Médio e para a Educação Profissional Técnica de nível médio às disposições do Decreto n ${ }^{\circ}$ 5.154/2004. Diário Oficial da União, Brasília, DF, 11 mar. 2005. Seção 1, p. 9.

. Conselho Nacional de Educação. Câmara de Educação Básica. Resolução $n^{\circ}$ 4, de 05 de outubro de 1999. Institui as Diretrizes Curriculares Nacionais para a Educação Profissional de Nível Técnico. Diário Oficial da União, Brasília, DF, 26 nov. 1999.

. Decreto $\mathrm{n}^{\circ} 2.208$ de 17 de abril de 1997. Regulamenta o $\S 2^{\circ}$ do art. 36 e os arts. 39 a 42 da Lei ${ }^{\circ}$ 9.394, de 20 de dezembro de 1996, que estabelece as diretrizes e bases da educação nacional. Diário Oficial da União, Brasília, DF, 18 abr. 1997.

. Decreto $n^{\circ} 5.154$ de 23 de julho de 2004. Regulamenta o $\S 2^{\circ}$ do art. 36 e os arts. 39 a 41 da Lei ${ }^{\circ}$ 9.394, de 20 de dezembro de 1996, que estabelece as diretrizes e bases da educação nacional, e dá outras providências. Diário Oficial da União, Brasília, DF, 26 jul. 2004.

. Lei n ${ }^{\circ} 9.394$, de 20 de dezembro de 1996. Estabelece as diretrizes e bases da educação nacional. Diário Oficial da União, Brasília, DF, 23 dez. 1996.

. Lei $\mathrm{n}^{\circ} 10.172$, de 09 de janeiro de 2001. Aprova o Plano Nacional de Educação e dá outras providências. Diário Oficial da União, Brasília, DF, 10 jan. 2001.

. Lei $\mathrm{n}^{\circ} 11.741$, de 16 de julho de 2008. Altera dispositivos da Lei $\mathrm{n}^{\circ}$ 9.394, de 20 de dezembro de 1996, que estabelece as diretrizes e bases da educação nacional, para redimensionar, institucionalizar e integrar as ações da educação profissional técnica de nível médio, da educação de jovens e adultos e da educação profissional e tecnológica. Diário Oficial da União, Brasília, DF, 17 jul. 2008a. 
BRASIL. Lei n ${ }^{\circ} 11.892$ de 29 de dezembro de 2008. Institui a Rede Federal de Educação Profissional, Científica e Tecnológica, cria os Institutos Federais de Educação, Ciência e Tecnologia, e dá outras providências. Diário Oficial da União, Brasília, DF, 30 dez. 2008b.

. Lei $n^{\circ} 13.005$, de 25 de junho de 2014. Aprova o Plano Nacional de Educação - PNE e dá outras providências. Diário Oficial da União, Brasília, DF, 26 jun 2014, Ed. Extra.

BRASIL. Ministério da Educação. Portaria $n^{0} 502$, de 09 de maio de 2012. Altera a Portaria $\mathrm{n}^{\mathrm{o}} 1.407$, de 14 de dezembro de 2010, para ampliar composição do Fórum Nacional de Educação. Diário Oficial da União, Brasília, DF, 10 maio. 2012. Seção 1, p. 23.

. Ministério da Educação. Portaria $n^{\circ} 1.407$, de 14 de dezembro de 2010. Institui o Fórum Nacional de Educação - FNE. Diário Oficial da União, Brasília, DF, 16 dez. 2010. Seção 1, p. 24.

. Projeto de Lei no 8.035 de 2010. Aprova o Plano Nacional de Educação para o decênio 2011-2020 e dá outras providências. Brasília, DF, 2010a. Disponível em <http://www.camara.gov.br/sileg/integras/831421.pdf>. Acesso em: 13 nov. 2013.

CONFERÊNCIA NACIONAL DE EDUCAÇÃO - CONAE, 2010, Brasília, DF. Documento final... Brasília, DF: Ministério da Educação, 2010.

, 2014, Brasília, DF. O PNE na articulação do sistema nacional de educação. Documento - referência.... Brasília, DF: Fórum Nacional de Educação, 2013.

FIDALGO, F; MACHADO, L. Dicionário da educação profissional. Belo Horizonte: Editora da UFMG, 2000.

MACHADO, L. R. S.; VELTEN, M. N. Cooperação e colaboração federativas na educação profissional e tecnológica. Educação e Sociedade, Campinas, v. 34, n. 125, p. 1113-33, out./dez. 2013. doi:10.1590/S0101-73302013000400006

MOURA, D. H. A relação entre a educação profissional e a educação básica na Conae 2010: possibilidades e limites para a construção do novo Plano Nacional de Educação. Educação e Sociedade, Campinas, v. 31, n. 112, p. 875-94, jul./set. 2010. doi:10.1590/S0101-73302010000300012 
PIRES, L. L. A. Educação tecnológica e formação profissional no contexto atual e o PNE 2011-2020: avaliação e perspectivas. In: DOURADO, L. F. (Org.). Plano Nacional de Educação (2011-2020): avaliação e perspectivas. 2. ed. Goiânia: Editora UFG; Belo Horizonte: Autêntica, 2011.

SHIROMA, E. O.; MORAES, M. C. M.; EVANGELISTA, O. Política educacional. 4. ed. Rio de Janeiro: Lamparina, 2011.

\section{Informações dos autores}

Anthone Mateus Magalhães Afonso: Doutorando em Educação, Universidade Estácio de Sá, Programa de Pós-graduação em Educação - UNESA/PPGE. Professor do Instituto Federal de Educação, Ciência e Tecnologia Fluminense. Contato: amateus@iff.edu.br/ anthone.mateus@gmail.com

Wania Regina Coutinho Gonzalez: Socióloga e Doutora em Educação. Professora da Universidade Estácio de Sá - UNESA, Programa de Pós-graduação em Educação e Cultura Contemporânea. Professora Adjunta da Universidade do Estado do Rio de Janeiro - UERJ, Faculdade de Educação da Baixada Fluminense. Contato: waniagonzalez@gmail.com 